\title{
Luciano ensaya la novela escénica: apariencia episódica y estructura unitaria de los Diálogos de los muertos
}

\author{
Lluís Gonzàlez Julià \\ Universitat de Barcelona \\ lluisgonzalezjulia@gmail.com
}

\begin{abstract}
Lucian tries out the scenes-novel: episodic appearance and unitary structure of the Dialogues of the Dead
\end{abstract}

\begin{abstract}
La especificidad de los Diálogos de los muertos de Luciano junto con el desorden con que los manuscritos han transmitido estas breves escenas ha provocado que se los considere piezas individuales, no interrelacionados entre ellos más allá de sus protagonistas y del contexto en el que se sitúan. Sin embargo, el examen detallado de las alusiones internas y de su estructura típica de novela de viajes permite reconsiderarlos como una estructura unitaria y cerrada, proponer un cambio de orden e, incluso, señalar como posibles interpolaciones a tres de los diálogos de la serie.
\end{abstract}

Palabras clave: Luciano; diálogo; innovación; novela; interpolaciones.
Lucian's Dialogues of the Dead belong to a very specific genre and their order in manuscript transmission is very confused. For those reasons, they have been usually considered as individual scenes without interrelation to each other, apart from their main characters or the world they move in. Nevertheless, a detailed examination of their inner allusions and their typical structure in travel-novels allows us to reconsider all of them as belonging to a unitary and close wholeness, to propose an order change and even to point three of these dialogues as possible interpolations in the series.

Keywords: Lucian; dialogue; innovation; novel; interpolations.

Gracias a la mezcla innovadora de distintos géneros literarios Luciano ocupa un papel destacado entre los autores griegos de su época. Los Diálogos de los muertos son parte de esta nueva clase de productos formados a partir de piezas de distintos modelos ${ }^{1}$. Estos textos, a los que se podría estar refiriendo sin

${ }^{1}$ Bompaire 1958, pp. 136-147, a pesar de dedicar su monumental estudio a la técnica de la imitación literaria de Luciano, no puede dejar de reconocer las aptitudes renovadoras y de creación original del Sirio; asimismo, su discípulo Reardon (1971, pp. 155-180) incluye su obra completa entre los autores de la Segunda Sofística que trabajan únicamente a partir de 
ningún problema quien dijo aquello de «Eres un Prometeo», son ciertamente una mezcla original de la comedia — producida generalmente en Luciano por la parodia, la sátira y la ironía ${ }^{2}$ - con el diálogo, forma prototípica con que se presentaba generalmente la filosofía. En efecto, los Diálogos de los muertos están formados por pequeñas escenas dramatizadas donde intervienen distintos moradores del Hades. En ellas Menipo y Diógenes, principalmente, protagonizan breves charlas cómicas con las que Luciano quiere mostrar cuán efímeras y vanas resultan ser las riquezas, la fama, el poder, la belleza y el resto de aspectos que la mayoría considera importantes en la vida, así como cuán falsas son las otras escuelas filosóficas en su concepción del momento de enfrentarse a la muerte.

Los treinta diálogos que componen esta obra de Luciano se consideran, habitualmente, una colección abierta de piezas independientes, sin más relación las unas con las otras que la temática común y sus protagonistas. De esta misma manera los presenta el manuscrito $\mathrm{B}$, arquetipo de la familia $\beta$, o el manuscrito $\omega$, uno de los mejores representantes de la familia $\gamma^{3}$. A pesar de

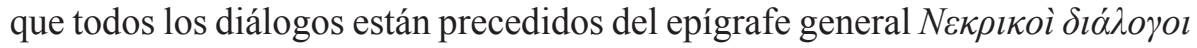
que anuncia el principio de la obra, el título de cada uno de ellos está rubricado como si de una nueva pieza se tratara y no como un subtítulo englobado en el conjunto de la colección. Incluso la numeración que computa las obras avanza con cada uno de los diálogos. Así, desde la edición de Jacobitz ${ }^{4}$ en el orden B para Teubner hasta la de Macleod $^{5}$ en el orden $\Gamma$ no se pudo poner en duda esta consideración ${ }^{6}$, ya que este manuscrito, el otro principal

la imitación retórica. Fue Anderson (1976a y 1976b) quien mostró los mecanismos concretos de la creación literaria a partir de la constante variación de unos mismos temas.

${ }^{2}$ Cf. Camerotto 1998 para un estudio detallado de la técnica de la parodia en la obra de Luciano. El valor humorístico de sus obras también fue puesto de manifiesto por los estudios sobre la sátira de Allinson 1926, Baldwin 1961 y Hall 1981, sin dejar de lado el trabajo de Branham 1989.

${ }^{3}$ Para el estudio de la tradición de las obras de Luciano en los manuscritos remitimos a la introducción general de la colección «Oxford Classical Texts» (Macleod 1972, pp. XII-XIX) y a las más modernas y detalladas introducciones de las colecciones «Budé» (Bompaire 1993, pp. LVI-CXXII) y «Alma Mater» (Jufresa, Mestre y Gómez 2000, pp. XXI-XXVII).

${ }_{4}^{4}$ Jacobitz 1836, pp. 186-256.

${ }_{5}$ Macleod 1961, p. i, se apoya sin más argumentos en la edición de Harmon 1913, p. xii, que, a su vez, sigue la opción de Nilén 1906.

${ }^{6}$ Cf. Bompaire 1958, p. 561, Schwartz 1965, pp. 56-64, Alsina 1966, p. 14, Baldwin 1973, p. 109, Anderson 1976a, p. 163 y 1976b, p. 272. 
representante de la familia $\gamma$, introduce cada diálogo con un subtítulo emplazado dentro del conjunto de la obra. La separación habitual entre obras distintas empleada en este manuscrito, una larga línea de puntos suspensivos, se encuentra únicamente entre el primer diálogo y la obra precedente, el Cínico, y el último diálogo y la obra que le sigue, los Diálogos marinos. Además, los diálogos aparecen ordenados de manera distinta en los manuscritos de esta familia que en los pertenecientes a la familia $\beta^{7}$.

Así pues, hasta el texto de Macleod 1987 en «Oxford Classical Texts» no aparecieron los primeros estudios sobre la estructura unitaria de esta obra. Navarro identificó unas secciones temáticas que distribuían los diálogos en tres partes, dedicadas la primera a Menipo, la segunda a personajes contemporáneos y la tercera a un conjunto misceláneo ${ }^{8}$. Ureña en su tesis doctoral profundizó en el estudio de los primeros diálogos de la colección también como secuencia introductoria9. Más tarde, Vilardo vislumbró una serie de estructuras argumentales que le hacen afirmar que las treinta piezas que constituyen los Diálogos de los muertos no son piezas independientes, sino una única obra sobre el mundo subterráneo de la que se pueden observar pequeños extractos constituidos por las escenas dramatizadas en los diálogos ${ }^{10}$. Sin embargo, tan sólo afirmó la unidad de la obra a partir de las semejanzas entre los personajes participantes y de los bloques temáticos que la integran, sin aducir ningún argumento complementario.

La técnica de la narración también había suscitado en Luciano un interés de ensayo y renovación ${ }^{11}$. El caso más llamativo son los Relatos verídicos, en los que Luciano retoma los principales tópicos de las obras periegéticas y novelescas para modelar una pieza narrativa sin igual en la literatura antigua, de tal modo que la crítica no llega a un acuerdo sobre su naturaleza ${ }^{12}$. Los Diálogos de los muertos, según nuestro parecer, constituyen un atrevimiento tan innovador como lo pueden ser los Relatos verídicos. En ellos, Luciano no

\footnotetext{
7 También aparecen en un orden distinto en ambas familias de manuscritos los Diálogos de los dioses y los Diálogos marinos; no sucede lo mismo, en cambio, con los Diálogos de las heteras, los cuales, además, no están incluidos en todos los manuscritos.

${ }^{8}$ Navarro González 1992, pp. 153-154.

${ }_{9}$ Ureña 1995, p. 71.

${ }^{10}$ Vilardo 1991, pp. XLII- XLVI.

${ }^{11}$ Anderson 1976b.

12 Para el análisis de las características narrativas de $V H$ cf. Anderson 1996, Georgiadou y Larmour 1998, Brandão 2001, pp. 253-259, y Cabrero 2006.
} 
sólo fusiona de manera ejemplar la filosofía cínica con las convenciones formales del género cómico, sino que también añade a esta mezcla un tercer elemento, el narrativo. Cada una de las piezas se entrelaza con las demás creando una narración que solamente se distingue de otras novelas de viajes por el punto de vista desde el que se presenta la historia ${ }^{13}$. En efecto, la concepción unitaria de todas las piezas que forman los Diálogos de los muertos y el análisis conjunto de su contenido, de su forma y de la técnica con la que están compuestos permiten percibir cuáles son las uniones que cohesionan esta novela de apariencia dramática ${ }^{14}$.

Una primera lectura de los Diálogos de los muertos permite observar cinco bloques temáticos que estructuran la obra: la llegada de Menipo al Hades, la situación de los semidioses una vez muertos, los lamentos de los humanos por la pérdida de sus bienes, los recuerdos de los héroes homéricos y, finalmente, un breve conjunto recapitulatorio y conclusivo. Sin embargo, esta secuenciación, que no presenta una cohesión argumentativa mayor que las propuestas aportadas hasta ahora, adquiere más consistencia si analizamos detalladamente la función de cada diálogo dentro del conjunto ${ }^{15}$.

Los primeros diálogos están destinados a presentar a los personajes principales, mostrar el programa de intenciones de la obra así como el escenario en que sucede la acción. Empieza la colección una conversación entre Diógenes y Polideuces (DMort. 1). El cínico, aprovechando que el Dióscuro va a subir al mundo de los vivos para intercambiarse con su gemelo, le encarga que le transmita un mensaje a Menipo. Para que Polideuces lo reconozca, Diógenes le proporciona la descripción típica de un filósofo cínico que sirve de presentación para el lector (1.1-2). Diógenes quiere proponerle que baje a reírse de los habitantes del submundo, antes ricos y poderosos, lo que constituye el verdadero programa de intenciones de la obra (1.1). El primer diá-

${ }^{13}$ Bompaire y Ozanam 2009, p. XVII, consideran que «les Dialogues des morts ne sont pas un voyage proprement dit» pero los incluyen en la colección de los relatos de viajes de Luciano.

${ }^{14}$ Cf. Vilardo 1991, p. XLII.

${ }_{15}$ Desde la época alejandrina, los poetas empezaron a concebir sus poemas dentro del conjunto en el que aparecerían publicados. También en Roma, la obra de Catulo u Horacio muestra esta preocupación por el valor de sus poemas dentro del conjunto en el que se publicaron, lo que nos parece muy semejante a la disposición de estos breves diálogos de Luciano en el conjunto de los Diálogos de los muertos; cf. Miller 1994, pp. 120-168. 
logo sirve también como introducción a los tipos de personajes que aparecerán a lo largo de la obra. Diógenes menciona a los filósofos (1.2), a los ricos y a los que se vanaglorian de su belleza (1.3), ejes principales hacia los que los cínicos dirigirán sus dardos.

En el segundo diálogo Hermes y Caronte presentan a Menipo. Uno de los muertos se niega a pagar el óbolo a Caronte. Alega no tenerlo porque en vida no utilizaba el dinero. Desesperado, Caronte pregunta a Hermes quién es ese «perro» que se ríe de todos los que se lamentan de haber muerto (2.3). Se reproducen aquí las mismas características con las que Diógenes había presentado en el diálogo anterior a Menipo. Además, otra referencia alusiva entre los diálogos permitía reconocer quién era esa figura que discutía con el barquero: los altramuces y la cena de Hécate (2.3), que, precisamente, le había encargado Diógenes a través de Polideuces en el diálogo primero (1.1). También aquí Luciano, usando su característica técnica de retrasar la información a modo de juego para el lector, calla el nombre de Menipo hasta el final del diálogo en la culminación de su presentación $(2.3)^{16}$.

En el tercer diálogo, tres de esos ricos y poderosos en vida de quienes Diógenes anunciaba a Menipo en el primer diálogo que se podría mofar, Creso, Midas y Sardanápalo, presentan sus quejas a Plutón por el trato que reciben de Menipo. Las referencias internas entre el primer diálogo y éste son numerosas. Luciano repite las mismas expresiones utilizadas para mencionar los lamentos de los muertos al recordar la vida ( $\mu \varepsilon \mu \nu \eta \mu \varepsilon ́ v o r ~ \tau \tilde{\omega} v$ óv 1.1

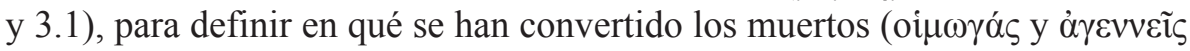

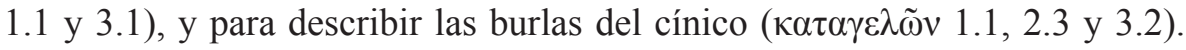
La alusividad y referencialidad interna entre los diálogos es uno de los factores más importantes de cohesión entre todas las piezas del conjunto; constituyen el procedimiento principal que permite un avance progresivo entre un tema y el siguiente sin cortes bruscos o repentinos dentro del hilo argumenta ${ }^{17}$. En numerosas ocasiones, serán el elemento esencial que conduzca el eje

${ }^{16}$ Ureña 1995, p. 91 ss., apoyándose en Bellinger 1928, p. 12 ss., analiza detalladamente la elipsis y el retraso de la aparición de los nombres de los personajes en los diálogos de Luciano. Esta técnica llevó a Beaupère 1967, p. 4, a pensar que los nombres de los personajes en algunas obras de Luciano como ésta pudieran haber sido incluidos por los escoliastas o los copistas medievales.

${ }^{17}$ Consideramos que las relaciones intertextuales entre cada diálogo de los Diálogos de los muertos pueden ser objeto de la misma consideración que las alusiones y referencias entre distintos autores que analiza Hinds 1998, pp. 1-51. 
temático. Estas alusiones y referencias internas son lo bastante numerosas y recurrentes para emplazar, además, cada diálogo en su lugar adecuado dentro de la obra.

Los diálogos 4, 5 y 6 completan el grupo introductorio. En ellos Menipo descubre la topografía del Hades y encuentra a sus principales moradores: el resto de dioses que lo regentan, los héroes más bellos, los más afamados, los personajes más ricos y los filósofos más ilustres. El descenso de Menipo se presenta de forma narrativa como cualquier otro descenso al Hades de la literatura griega, sin obviar las resonancias que se desprenden en este recorrido de otras obras lucianeas ${ }^{18}$. El protagonista llega con Hermes hasta el barquero Caronte. En el cuarto diálogo, Menipo se encuentra con Cerbero, después realizará su primera vista del Hades, acompañado por Hermes, a modo de guía, en DMort. 5 y, seguidamente, se topará en DMort. 6 con el último personaje del Hades que faltaba por presentar, el juez Éaco.

También los diálogos cuarto, quinto y sexto tienen referencias internas que refuerzan su unión argumental. DMort. 4 empieza con una clara alusión a los diálogos anteriores en los que se presentaba a Menipo como perteneciente a la secta de los cínicos (4.1). Sirve esta pieza como el fin de la presentación de ambos protagonistas. Además, ya que con ellos se compara la actitud de Sócrates, se forma una pequeña estructura circular que terminará en 6.5 con la aparición de éste. Los diálogos quinto y sexto ponen sucintamente en escena a algunos de los personajes más ilustres. La belleza mítica de Aquiles y Helena es parodiada en una situación en que sus calaveras no conservan ya ninguno de sus rasgos distintivos (5.1). Los grandes héroes homéricos han perdido su grandeza (6.1), los reyes y tiranos - que aparecen aquí calificados como $\kappa \alpha \theta \dot{\alpha} \rho \mu \alpha \tau \alpha$ del mismo modo que en 1.1- han perdido sus posesiones (6.2), y los filósofos, sus creencias: Pitágoras ya come habas (6.3), Empédocles desmitifica su suicidio en el Etna (6.4) y Sócrates ya sólo se dedica a pasar el tiempo acompañado de jóvenes (6.6).

Estos diálogos muestran claramente el mecanismo de progresión a través del argumento común de los Diálogos de los muertos: el viaje por el Hades. Como hemos dicho, Luciano construye esta colección de escenas con una técnica muy parecida a la empleada en los Relatos verídicos. Entre las coin-

18 Bompaire 1958, pp. 365-378 (retomado y actualizado en Bompaire 1998, pp. 259-262), analiza la influencia de la tradición literaria de los descensos al Hades presente en Luciano. 
cidencias de ambas obras, llama especialmente la atención el mecanismo de cohesión de las diversas y heterogéneas situaciones que se plantean. Nadie osaría decir que las distintas situaciones presentadas en los Relatos verídicos no forman parte de una misma pieza, ya que todos los elementos que los integran están coordinados por un único narrador que organiza las aventuras a través de un viaje con el que se va desplazando de un lugar a otro ${ }^{19}$. Éste es, pues, el mismo mecanismo que opera en los Diálogos de los muertos. Es un mecanismo más sutil y elaborado que en los Relatos verídicos, que se reproduce en todos aquellos momentos en los que se debe hacer un cambio de bloque temático demasiado fuerte para que la leve alusividad lo soporte. Sin embargo, la falta de un narrador característica de los géneros dramáticos que anuncie los movimientos de los personajes y los cambios de escena no impide que éstos se puedan llevar a cabo de la misma manera ${ }^{20}$. Luciano, recreando magistralmente las convenciones del género, consigue que sean los propios personajes de sus diálogos los que dibujen el viaje por la topografía subterránea, a partir de los desplazamientos descritos por sus palabras. Así, después de descubrir de boca de Hermes que girando hacia la derecha tras cruzar las puertas de Cerbero se encuentran los héroes homéricos (5.1), Menipo recurre a Éaco para saber más de la topografía por la que se desarrollará el viaje de los Diálogos de los muertos. Menipo le pide al juez que le haga una $\pi \varepsilon p$ iń $\eta \sigma ı \varsigma$ del Hades $(6.1)^{21}$. Éaco, como si hubiera leído los anteriores diálogos, enumera los lugares por los que ha pasado Menipo, constatando que ya conoce al barquero Caronte, a Cerbero, la laguna y el Piriflegetonte (6.1). Seguidamente, Éaco le muestra dónde están los héroes, los reyes y los filósofos y le permite proseguir en solitario su viaje. Menipo decide ir a dar una vuelta para seguir riéndose de los muertos, en especial de Creso y Sardanápalo, que siguen llorando por las posesiones que han perdido (6.6). El verbo usado tanto por Menipo como por Éaco es ö́ $\varepsilon \psi \mu 1$, 'marcharse', un verbo de movimiento que denotará el desplazamiento $\mathrm{y}$, a la vez, un cambio de escena y de bloque temático ${ }^{22}$.

${ }^{19}$ El motivo del viaje en las novelas constituye el centro de atención de los estudios de André y Baslez 1993, Saïd 1994, Roussel 2003 y Gómez Espelosín 2009.

${ }^{20}$ Whitmarsh 2004 describe el papel que juega el autor-narrador en las obras de Luciano, aunque no analiza el caso de los Diálogos de los muertos.

${ }_{21}$ Sobre el género periegético cf. Bianchetti 1998 y Pretzler 2007.

${ }^{22}$ Ureña 1995, p. 87, señala que el «movimiento escénico» es un recurso tópico que suele indicar inicio y fin en los diálogos, tanto breves como extensos, de Luciano. 
Es precisamente después del diálogo sexto donde cabe un lugar aceptable para la recolocación de DMort. 3. La principal razón nos remite al final de DMort. 6. Allí, Menipo decide ir a reírse de Creso, Midas y Sardanápalo, precisamente los personajes que intervienen en el tercer diálogo. Por otro lado, es el propio Éaco quien presenta, en el diálogo sexto, estos tiranos a Menipo, ya anteriormente en escena quejándose ante Plutón por las burlas de Menipo. Tampoco resulta incoherente el recorrido topográfico que implica este diálogo, ya que, según la descripción del Hades de Éaco, entrando a la derecha, están los héroes, después Creso, Midas y Sardanápalo, y, finalmente, los filósofos. En su recorrido, Menipo se había parado a mofarse de los héroes y de los filósofos. Ahora, Menipo retrocede y se encuentra con los tiranos, antes de regresar hacia la entrada donde hallará de nuevo las figuras legendarias. Además, la aparición aquí de Plutón concluiría la presentación gradual de los personajes principales del Hades: Hermes, el barquero Caronte, el portero Cerbero, el juez Éaco y, al fin, el rey Plutón. Por otra parte, el diálogo con los tiranos termina con una mención al célebre dicho délfico retomado por Sócrates «Conócete a ti mismo» (3.2). La técnica de la alusividad aportaría aquí un nuevo nexo entre escenas, ya que este final retomaría la figura del filósofo ateniense, que Menipo ha dejado atrás en el diálogo anterior, al lado de la laguna. Este diálogo sería una escena de transición entre bloques, representando una parte del desplazamiento espacial dentro del Hades y cerrando el bloque introductorio, ya que el diálogo termina con la conclusión de que Menipo seguirá burlándose de los moradores del inframundo. Estos diálogos de transición aparecerán también entre los siguientes grandes bloques temáticos ${ }^{23}$.

Después de separarse de los tiranos, Menipo encuentra a Tántalo, su primera víctima entre los héroes, a los pocos pasos, siguiendo el camino marcha atrás por la orilla de la laguna (7.1). Este diálogo inaugura una serie de piezas, que se extienden hasta DMort. 13, centradas en la relación de los héroes con la muerte. La alusividad intertextual de estos diálogos volverá a ser el elemento que los cohesione y permita, a través de pequeñas asimilaciones entre los personajes, trazar un progreso argumental que va más allá de

${ }^{23}$ Encontramos escenas de transición como las de los Diálogos de los muertos también en las Relatos verídicos, en pasajes como VH 1.6, 10 o 29 y VH 2.2 o 29; cf. Hist.Cons. 55 para la teoría literaria de Luciano sobre las transiciones graduales en las narraciones. 
la coincidencia temática. En el primero de ellos, Menipo intenta hacer ver a Tántalo que su suplicio no es del todo trágico, porque ningún muerto puede beber en el Hades; todos comparten con él la condena de no volver a tomar jamás agua como lo hacían en la Tierra (7.2). Éste es, precisamente, el nexo que une este diálogo con el siguiente $\mathrm{y}$, a la vez, une esta pieza con la anterior: Menipo se propone que Tántalo se dé cuenta de cuál es la naturaleza de los muertos, al intentar que se comprenda a sí mismo —al modo socráticoen tanto que fallecido.

En DMort. 8 Quirón argumenta, ante las preguntas de Menipo, que dejó de ser inmortal porque ya había tenido bastante con la monotonía de la vida. Añade, además, que estando muerto ya no tiene algunas de las preocupaciones propias de la vida, como la sed y el hambre (8.2), palabras que, pronunciadas inmediatamente después de las quejas de Tántalo por su suplicio (7.2), no dejan de acrecentar la ligazón entre ambos diálogos en una mutua potenciación del valor humorístico de cada pieza ${ }^{24}$. En este caso, el resultado conseguido por Luciano no hubiera sido el mismo de haber presentado los diálogos independientemente o colocados en algún otro orden.

El diálogo octavo, a su vez, forma también un nexo contextual con el diálogo que le sigue. En DMort. 9, Menipo interroga a Tiresias acerca de la tradicional cuestión sobre qué género humano vive mejor ${ }^{25}$. Estamos ante un personaje completamente contrario al del diálogo anterior. Quirón llegó al Hades aburrido de la monotonía que le apesadumbraba en vida, mientras que Tiresias gozó de una innumerable cantidad de vivencias. El contraste entre ambos personajes acrecienta de nuevo el valor cómico de cada uno de los diálogos y crea un nexo a contrario entre ambas piezas. Tiresias, además, era en vida un adivino y se caracterizaba, como rasgo de gran sabiduría, por su ceguera. No obstante en el Hades no es ésta una característica que permita reconocerle, ya que incluso los personajes con mejor vista, como Linceo, están privados de sus ojos (9.1).

Esto sirve a Luciano para introducir un argumento que le permitirá avanzar en la reflexión sobre la relación de los héroes con la muerte en los diálogos

${ }^{24}$ La comparación es uno de los procedimientos retóricos más importantes para aumentar e intensificar las virtudes o defectos de personajes u objetos, bien sea a modo de elogio o como escarnio; cf. Theo, Prog. 113-114 y Hermog., Prog. 18.

${ }_{25}$ Ésta es una de las preguntas tópicas que se le ha formulado al personaje de Tiresias en numerosas obras de la literatura; cf. E., Med. 251, Ou., Met. III 316-338 y Luc., Men. 21. 
sucesivos: la figura del héroe adivino que incluso después de muerto sigue ofreciendo sus vaticinios en el otro, nuestro mundo. Trofonio, en DMort. 10, ante una pregunta de Menipo sobre su naturaleza después de muerto, afirma ser héroe y adivino (10.1). Luciano, después de burlarse de la práctica de la adivinación ${ }^{26}$, le cuestiona la naturaleza heroica. Menipo, pues, pregunta a Trofonio qué es un héroe (10.2). El adivino responde con la definición tradicional: un héroe es mitad hombre y mitad dios (10.2). Menipo, fiel a su estilo, ironiza sobre su respuesta y bromea diciendo que no sabe dónde ha ido a parar la mitad divina ya que le ve como un cadáver completo (10.2).

El diálogo siguiente recupera el personaje de Diógenes, probablemente para preparar la presentación en escena de uno de los cínicos más antiguos, Antístenes, en DMort. 22 y retrasar la cronología real de los personajes que aparecerán en los diálogos posteriores. La reciente muerte de Alejandro - que aparecerá a continuación - no puede suceder en el mismo ambiente de Menipo o $\operatorname{Crates}^{27} \mathrm{y}$, más aún, la lejanía temporal de los héroes del cuarto bloque, en que Odiseo aún no ha muerto, se debe preparar con una progresión escalonada. A pesar de este cambio de personaje y época, el hilo argumental de la obra continúa a través de la problemática suscitada a raíz de la naturaleza heroica. El gran salto que a primera vista provoca el cambio de personaje principal y de su interlocutor es rápidamente salvado por Luciano con el uso de la misma expresión con que se cerraba el diálogo anterior. Heracles es descrito por Diógenes como un cadáver completo (11.1). También este cínico cuestiona la ubicuidad de la figura heroica identificando completamente al cadáver de Heracles con el personaje que protagonizó todas las gestas. Como estaba previsto en el programa de intenciones de la obra, esta disputa agonística lleva también a Diógenes a la prevista burla de los mejores personajes épicos (11.5).

Cierran este segundo gran bloque dos diálogos dedicados a Alejandro. DMort. 12 y 13, siguiendo el hilo argumental de los diálogos anteriores, le

${ }^{26}$ Entre las críticas de Luciano a su sociedad contemporánea, ocupan un lugar destacado las creencias en los falsos adivinos, especialmente en Alejandro o el falso profeta.

${ }^{27}$ Alejandro Magno murió el año 323 a. C., mientras que Menipo de Gádara vivió durante el siglo III a. C. Asimismo, se sitúa el floruit de Crates de Tebas en el año 325 a. C. Por contra, Diógenes de Sínope puede entablar conversación con Alejandro en el Hades porque, según cuenta la tradición (D.L. VI 79 y Plu., Mor. 717c), ambos murieron en la misma fecha. Antístenes, considerado el fundador de la escuela cínica, había muerto en el año 365 a. C., a los ochenta años de edad. 
sitúan en una aporía al indagar sobre su pretendida inmortalidad. Alejandro se encuentra en el Hades con su verdadero padre, quien le espera para recriminarle que hubiera fomentado la leyenda que decía que era hijo de Ammón. Filipo argumenta que, ante la evidencia de su muerte, él debe ser su verdadero padre (12.1). Alejandro sólo puede escudarse en la falsa profecía que le ofreció uno de esos adivinos de los que Menipo se ha burlado en DMort. 9 y 10. La historia sirve a Luciano para concluir definitivamente que los héroes no son más que personas que tienen su fin, como las demás, en forma de cadáver en el Hades. Filipo también pregunta a Alejandro si no cree que la ayuda divina resta méritos a sus gestas. Alejandro, desconocedor de que Diógenes acaba de burlarse de Heracles en el diálogo anterior, presenta a este héroe como argumento de autoridad para su reputación al considerar que los humanos les ponen en parangón. Este parangón, que Alejandro aduce con fines positivos, no hace más que disminuir sus cualidades heroicas, puesto que, como Heracles, Alejandro es únicamente un cadáver y así precisamente es descrito por su padre en su última intervención (12.6).

Diógenes toma el relevo de Filipo para burlarse de Alejandro en el siguiente diálogo. Esta pieza enlaza con la anterior por la primera intervención de Diógenes, quien se admira también de que Alejandro esté muerto como los demás. No tendría sentido, sin embargo, para el conjunto de la obra, que Luciano incorporara otro diálogo para tratar los mismos temas que el anterior, repitiendo las mismas chanzas. Este diálogo, pues, actúa a modo de engranaje temático. Es una sutil transición que enlaza la temática heroica analizada en los diálogos anteriores con un nuevo bloque de contenido. Después de recordar a Alejandro todos los bienes de que disponía en vida, Diógenes le advierte que no es posible recuperar todo lo que uno ha dejado arriba después de cruzar la laguna y le aconseja, además, que no rememore todas las riquezas, la felicidad, la fama o el poder que tenía, ya que todo ello no le traerá nada más que sufrimiento (13.3-4). Por ello, debe beber el agua de la fuente Lete, del olvido, que ayuda a no sufrir por los bienes perdidos (13.6). Gracias a Alejandro, Luciano ha conseguido dejar atrás la problemática heroica y ha introducido plenamente el nuevo contexto que ocupará el siguiente bloque de diálogos, centrados en el recuerdo de la vida pasada, en especial, por parte de personajes mundanos obsesionados por sus herencias. Refuerza el nexo la opinión que Alejandro tiene de su maestro Aristóteles, un farsante que le agasajaba para obtener grandes be- 
neficios $(13.5)^{28}$. Narrativamente, el cambio está denotado por una fuerte imagen de movimiento. Diógenes ve a Clito y a Calístenes, que han descubierto la llegada de Alejandro al Hades y se dirigen contra él no con buenas intenciones. Diógenes exhorta a Alejandro a marcharse de allí (13.6). Aunque el movimiento no corresponde al cínico, la fuerza cinética de la expre-

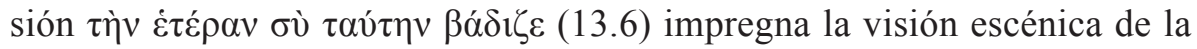
obra y arrastra al público a un lugar distinto de aquel en que se han producido las conversaciones sobre la naturaleza heroica.

En DMort. 14, Caronte y Hermes están conversando. La escena nos reconduce marcha atrás hacia el mismo lugar donde Menipo inició su recorrido por el Hades. Nos acompaña Diógenes, observando como nosotros la escena representada hasta DMort. 19. Aparecerá en escena de nuevo en DMort. 20 para mofarse, junto con Antístenes y Crates, de los personajes que protagonizan los diálogos intermedios. En ellos, varios difuntos narran entre lamentos las circunstancias de su muerte, todas ellas, relacionadas con la ambición desmesurada por recuperar una herencia que perdieron estúpidamente. El doloroso recuerdo de los bienes perdidos de que Diógenes advertía a Alejandro se muestra en este bloque en la más despiadada sátira de Luciano. Los testamentos históricos ${ }^{29}$, así como la ficción basada en hechos reales conservada en las declamaciones sobre desheredados, madrastras o envenenamientos ${ }^{30}$ corroboran la realidad de las situaciones presentadas en DMort. 16, 17, 18 y 19. Inician la serie, pues, Hermes y Caronte haciendo cuentas de las deudas del barquero. Caronte no puede pagar lo que debe a Hermes porque, en tiempos de paz, no hay suficientes clientes para cubrir los gastos ${ }^{31}$. Hermes, sin embargo, no se muestra apesadumbrado, sino que se lamenta de que el dinero sea la causa de la mayoría de las muertes más recientes, mientras que los muertos habían perecido antaño por causas más nobles (14.2). Con sus lamentos, Hermes termina la primera introducción a este bloque temático.

\footnotetext{
${ }^{28}$ Esta crítica contra los beneficios que consiguen los falsos aduladores de los personajes ricos e ilustres es ampliamente desarrollada por Luciano en Timón.

${ }^{29}$ Sirvan como ejemplo los testamentos conservados en los papiros Mitteis, Chr. 316, POxy. XXXVIII 2857 o POxy. XXII 2342.

${ }^{30}$ Luciano mismo ofrece un ejemplo de este tipo de declamación en su obra El hijo desheredado.

${ }^{31}$ Este dato fue tomado por Nissen 1888, pp. 244-245, y por Helm 1906, p. 195 y p. 198 n. 1, para fechar el diálogo en el año 166-167 d. C.
} 
En DMort. 15, el interlocutor de Hermes ha cambiado. Hermes está ahora con Plutón, el cual, sin embargo, mantiene el mismo tema de conversación. Plutón está tomando decisiones sobre el fallecimiento de un grupo de jóvenes avariciosos y deseosos de herencias, burlándose él mismo de las falsas expectativas que se habían creado (15.1). Hermes, obedeciendo las órdenes de Plutón, se dirige a buscar a algunos de estos hombres corrompidos por el afán de riquezas obtenidas en herencias a costa de la muerte de otros.

Los cuatro diálogos siguientes ponen en escena los lamentos de esos hombres al perder el dinero que habían estado buscando. A primera vista son cuatro diálogos en los que Luciano ha repetido el mismo argumento y ha jugado con un mismo tema para crear una serie de variaciones independientes - citando a Anderson ${ }^{32}$ - , colocados en esta posición por la coincidencia temática con las dos piezas precedentes. No obstante, estos cuatro diálogos se deben entender como una única escena que continúa la situación de los diálogos anteriores, vista desde cuatro ángulos distintos. La última intervención de Hermes en DMort. 15 computa en siete el número de fallecidos que bajan al Hades a causa del decreto contra los buscadores de herencias que acaba de pronunciar Plutón (15.2). En efecto, son cinco los hombres que aparecerán en fila en los próximos tres diálogos, sumándose a Carino y Damón, los dos jóvenes que Plutón había pedido a Hermes al principio de DMort. 15. Terpsión, Zenofanto, Calidémides, Cnemón y Damnipo son los desafortunados que sufren la desdichada muerte. El primero de ellos conversará con Plutón sobre la decisión que ha tenido de hacerles perecer antes que sus testadores. Los otros cuatro se narrarán entre ellos su inesperado y característico fin, ya que cada uno representa una situación particular. Terpsión, en DMort. 16, ha muerto a sus treinta años antes que el anciano del que pretendía obtener la herencia. En DMort. 17, Calimedes narra a Cneofanto que murió atragantado a causa de un excesivo afán en su parasitismo, ya que preparó un veneno para un anciano durante un convite, pero por error bebió él mismo de la copa envenenada. En DMort. 18, Cnemón cuenta cómo decidió hacer testamento en favor de Hermolao para que éste hiciera lo mismo y Cnemón pudiera obtener su herencia. Desafortunadamente, el techo de una casa le cayó encima a Cnemón y toda su herencia pasó, al contrario de lo que pretendía que sucediera, a las arcas de Hermolao. Finalmente, DMort. 19 presenta la situación desde un punto de vista contrario. Símilo explica que ha

${ }^{32}$ Anderson 1976a. 
muerto treinta años antes que el resto, de manera que no puede englobarse entre las víctimas de la orden de Plutón, y Polístrato es un anciano que se regocija del tiempo que ha vivido feliz por la adulación de los jóvenes. No puede, por tanto, ser contado entre ellos. Sin embargo, el contrapunto que este personaje ofrece permite a Luciano resumir en pocas palabras y entre burlas los peligros que acechan a los buscadores de herencias (19.3) ${ }^{33}$. El viejo mismo propone la enseñanza moral al reconocer de qué modo jugaba con sus aduladores cambiando su testamento hasta el último momento para dejarles a todos bien (19.3).

Diógenes y Crates han podido observar en primera persona la escena que Luciano nos ha presentado de manera tetrangular. DMort. 21 y 22 funcionan como un nuevo engranaje entre bloques temáticos. En DMort. 21, los cínicos recuperan el protagonismo. La escena que acaban de presenciar les hace rememorar otro caso parecido. Crates narra cómo dos hombres ricos que testaron en favor el uno del otro murieron al mismo tiempo y quedaron ambos privados de sus riquezas. Esta desdichada historia hace reflexionar a Diógenes sobre las herencias que se podrían dejar los cínicos entre ellos: un bastón, un tonel y una alforja con pocos altramuces ${ }^{34}$. Crates se congratula de que la pobreza sea la mejor herencia que Diógenes pudo haber recibido de él mismo, y que él la heredó de Antístenes (21.3). Gracias a ello, los cínicos no tienen de qué lamentarse en el momento de la muerte.

Habiendo sido mencionado Antístenes, puede aparecer ya en escena. DMort. 22 representa un verdadero diálogo de transición, de nuevo con una imagen de movimiento que cambia la escenografía en que se sitúa la acción (22.1). Diógenes propone a sus compañeros que vayan a ver a los nuevos muertos. Este diálogo se presenta como una charla de tiempo libre que servirá como digresión a la novela, como un intervalo de descanso ubicado entre el fin de un tema intenso y otro de gran trascendencia, los héroes homéricos. Crates y Diógenes explican cómo descendieron al Hades, y cómo se lamentaban sus compañeros. Y entre historia e historia, los tres cínicos se acercan a la orilla de la laguna donde llegan los nuevos muertos (22.8). Las

${ }^{33}$ En Gall. 14 Luciano pone en escena a un pobre, llamado Simón, quien recibe también la herencia de un familiar. También allí, Menipo afirma que el oro tiene la capacidad de transformar en atractivas a las personas feas, ya que desde ese momento innumerables mujeres no pararon de acercarse a ese pobre.

${ }^{34}$ Luciano vuelve a burlarse de los hombres que se lamentan durante su bajada al Hades por la pérdida de sus bienes en Cat. 20. 
palabras de los protagonistas nos sitúan en un nuevo espacio escénico, diferente al de la escena anterior. Es el justo momento en que están desembarcando nuevos moradores del Hades. Lamentándose todos, un anciano ${ }^{35}$ es escogido por los cínicos para averiguar los motivos de sus llantos. El viejo no les da ninguna razón en especial; solamente se lamenta, dice, porque la luz del día es más grata que el estar muerto (22.9). Después de responderle que esas son preocupaciones más propias de los jóvenes y de dejarle marchar, los cínicos deciden nuevamente cambiar de emplazamiento para que nadie sospeche que están planeando una fuga.

DMort. 23 inicia el bloque más heterogéneo, parecido a un cajón de sastre donde se acumulan una serie de diálogos sin relación mutua y de contenido muy dispar. No obstante, también un sutil hilo argumental enlaza las piezas. DMort. 22 no constituye una digresión tan banal como puede parecer. Su final abre el camino a un nuevo episodio que da coherencia a los diálogos DMort. 23, 26 y 27, y permite enlazar a estos la conclusión final del conjunto de la obra. Diógenes, Crates y Antístenes se han marchado y han dejado solo al lector en las puertas del Hades (22.9). Como en DMort. 5, cuando Menipo está entrando en el mundo subterráneo, lo primero que se atisba son los héroes homéricos, emplazados a su derecha, al lado de la laguna. Sin la necesidad de un gran desplazamiento escenográfico, a ellos se dirige de nuevo la atención de la obra. Áyax, Agamenón y Aquiles son los principales personajes que ocupan estos tres diálogos. La unión con el hilo argumental dejado en suspense en DMort. 22 se retoma inmediatamente. La alusividad metatextual de las últimas intervenciones del viejo y de Diógenes en el diálogo anterior están dirigidas a clarificar el nexo argumental con los diálogos sucesivos y eran fácilmente reconocibles para las personas instruidas de la época $^{36}$. Las palabras con las que el anciano hace prevalecer la luz sobre la muerte están llenas de resonancias épicas; son palabras que según Diógenes son más propias de un joven (22.9), de alguien que termina los días antes de tiempo; son, en definitiva, las palabras con las que Aquiles se dirige a Odiseo

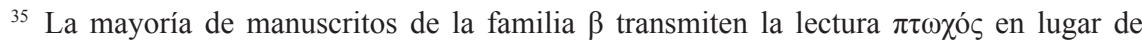
$\gamma \varepsilon \dot{\varepsilon} \omega v$, impidiendo que cobre sentido el juego de referencias que se puede establecer al escoger la opción de los manuscritos $\gamma$.

${ }^{36}$ La educación, basada en gran medida sobre la lectura de los clásicos, hacía posible que los auditorios reconocieran con facilidad todas las referencias metatextuales que los sofístas incluían en sus discursos; cf. Morgan 1998 y Cribiore 2001, pp. 185-219. 
en la vékvia homérica ${ }^{37}$. Aquiles y Odiseo centrarán el eje temático de los siguientes diálogos.

En el primero de ellos (DMort. 23) Aquiles y Odiseo, a pesar de su ausencia, están muy presentes. El descenso al Hades de Odiseo, motivo que sirve de nexo argumental entre el anterior diálogo y el nuevo, había puesto de manifiesto en el Hades las rivalidades entre los héroes. Agamenón pregunta a Áyax las razones por las que no dirigió la mirada a Odiseo en su descenso. Áyax le explica las acciones de Odiseo que le provocaron la locura que le llevó al suicidio. En este diálogo (23.1), al igual que en 26.3, se explicita que Odiseo aún no está muerto. Esto implica que la narración ha realizado un salto cronológico, un viaje también en el tiempo. La ausencia de personajes históricos permite a Luciano imaginar las conversaciones que debieron tener los héroes homéricos después de morir. Después de cuatro diálogos, el hilo argumental conducirá de nuevo la narración hacia el presente con la reaparición de los cínicos en DMort. 29.

Mientras tanto, el descenso de Odiseo marcará también el paso a DMort. 26, ya que Antíloco pregunta los motivos por los que Aquiles pronunció la célebre frase a la que alude el final de DMort. 22. Luciano resuelve aquí la alusividad suspendida entre los diálogos haciendo que Antíloco, en su primera intervención, reproduzca las palabras de Aquiles (26.1). Él mismo es el encargado de plantear la paradoja que atormenta a todos estos héroes homéricos en el Hades: escogieron una muerte temprana a cambio de una buena fama (26.1), pero, como reconoce el propio Aquiles, el recuerdo de la vida es muy difícil de sobrellevar (26.4). Antíloco, como si hubiera escuchado las intenciones de Diógenes y Menipo al principio de la obra, hace callar a Aquiles, porque teme que alguien pueda reírse de su malestar (26.4). El Pélida se lamentaba de haber sido tan ingenuo de creer a los aedos, quienes le empujaron a preferir una vida corta pero afamada sin advertirle que después de la muerte nadie conserva la grandeza de la vida, sino que la muerte trata a todos por igual y los equipara (26.2). Las palabras de Aquiles bien podrían haber sido pronunciadas por los Menipos o Licinos de cualquier obra de Luciano. Aquí, sin embargo, la enseñanza moral cínica es reforzada por la autoridad del protagonista del principal libro escolar del sistema educativo grecorromano ${ }^{38}$.

37 Od. XI 489-491.

${ }^{38}$ Homero era el autor utilizado por excelencia en las escuelas, y, en especial, parece que la Ilíada fue más empleada que la Odisea; cf. Morgan 1998, pp. 144-151, Cribiore 2001, 
Las dos sentencias pronunciadas por Aquiles y Antíloco en DMort. 26 inician la conclusión de la obra, que se hará patente, especialmente, en los tres últimos diálogos del conjunto. Se hace necesaria, no obstante, una pieza que armonice el desenlace y que ayude a recoger los últimos elementos aportados en los diálogos homéricos para que Diógenes y Menipo puedan cerrar los Diálogos de los muertos. Dos diálogos, DMort. 27 y 28, se ocupan de esta tarea. El primero está unido al anterior por la incapacidad del héroe de olvidar su pasado. Ahora es Protesilao quien no puede dejar de pensar en la mujer que dejó viuda para ir a luchar a Troya, lugar donde, ansioso de la fama del combate, desembarcó en primer lugar y también el primero encontró la muerte. Y ya que Éaco, su interlocutor en este diálogo, no sucumbe a sus súplicas, Protesilao dirige sus peticiones en el segundo diálogo a Plutón y Perséfone. Protesilao desea volver a subir (28.1) por el amor que siente. No es el único, alega, ya que a otras, como Eurídice o Alcestis, también se les concedió la subida por causas amorosas $(28.3)^{39}$. La anábasis tiene aquí una triple función. Protesilao utiliza como argumento en su favor las otras anábasis que tanto los reyes del Hades como la audiencia conocen. En segundo lugar, la subida de Protesilao cohesiona este subgrupo intermedio con el resto de diálogos homéricos centrados en la vé́kvia de Odiseo. Finalmente, al concedérsela Plutón y Perséfone, Luciano construye una estructura circular que engloba y da coherencia a todas las piezas de la obra desde que, en el primer diálogo de la colección, Polideuces lleva al mundo el encargo de Diógenes para Menipo.

La obra debe terminar con una conclusión que sirva de recapitulación de los principales argumentos filosóficos del cinismo que han aparecido esparcidos entre las distintas escenas de esta narración episódica, y que, a su vez, despida a sus protagonistas. Esta conclusión está también ligada al hilo argumental a partir de la intertextualidad entre diálogo y diálogo. Plutón concede a Protesilao que suba a buscar a su esposa, pero, puesto que al morir se ha convertido en una calavera irreconocible, le ayuda a recuperar su antigua fisonomía (28.3). Los cuerpos, en efecto, pierden en el Hades la belleza y la fuerza de que gozaban en la vida y que les hacía destacar (29.2-3). Por lo tanto, Mausolo, el interlocutor de Diógenes en el penúltimo diálogo

pp. 194-197 y Bouquiaux-Simon 1968 para un estudio completo de las alusiones homéricas en Luciano.

${ }^{39}$ Luciano retomará estos mitos en Luct. 5. 
de la obra, no tiene de qué vanagloriarse después de la muerte y de nada resultan beneficiosos todos los monumentos que ha dejado arriba en la Tie$\mathrm{rra}^{40}$. Mausolo, exasperado por tener la misma consideración en el Hades que el cínico Diógenes, es el objeto de la última y conclusiva mofa del cínico: mientras Mausolo llore lo que ha dejado arriba, Diógenes se burlará de él. Se cumple así el programa de intenciones que el cínico había pronunciado al principio de los Diálogos de los muertos. Únicamente queda la conclusión del protagonista de la obra. DMort. 30 mantiene el fin del hilo argumental centrado en el aspecto cadavérico de los muertos. Aquí Tersites y Nireo están disputándose la primacía en la belleza física. Menipo resuelve la disputa mostrando que en el Hades nadie conserva la belleza que caracteriza los cuerpos vivos y que allí todos son calaveras indistinguibles las unas de las otras (30.2). Si Aquiles, unos diálogos atrás, increpaba a los aedos por haberle engañado al hacerle preferir la fama a la vida, Homero vuelve a ser aquí el bastión tradicional franqueado por el pensamiento cínico de Lucia$\mathrm{no}^{41}$. Las bondades contadas por Homero no tienen ninguna importancia para Nireo y Tersites tampoco ahora; fueran como fueran, deben comprender, ellos pero también nosotros, el destinatario de la obra, la conclusión que se desprende de las últimas palabras de Menipo: en el Hades, donde impera

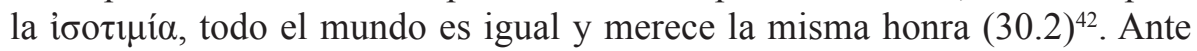
la evidencia que proporcionan cada una de las piezas de los Diálogos de los muertos, el lector, como Tersites (30.2), no puede hacer más que aceptar la admonición que Luciano ha desarrollado a través de la historia del último viaje de Menipo.

Tres diálogos, pues, parecen no tener cabida dentro de este conjunto unitario cohesionado a partir del motivo del viaje y de las referencias intertextuales. Son DMort. 20, 24 y 25. El primero ellos, DMort. 20, pone en escena a Caronte y Hermes obligando a distintos personajes tipo a deshacerse de sus bienes terrenales para poder cruzar la laguna. Son tres, principalmente, los problemas estructurales que plantea. En primer lugar, este diálogo está situado entre el gran bloque de personajes que han perdido sus herencias,

${ }^{40}$ Mausolo es también objeto de las burlas de Menipo en Nec. 17.

${ }^{41}$ A pesar de que en muchos pasajes de otras obras, como IConf. 1-2, Gall. 6 o ITr. 39, Luciano critique personalmente a los poetas, es el propio Zeus, en Bis Acc. 1 quien increpa a Homero por las mentiras que contaba sobre ellos en sus poemas.

${ }^{42}$ Cf. Brandão 2001, pp. 159-162. 
interrumpiendo la clara secuencia compositiva. Asimismo, después de diecinueve diálogos, Menipo es de nuevo presentado, ya que Hermes le pide que se identifique antes de subir a la barca de Caronte (20.2). Además, Menipo declara en este diálogo que ha tirado, antes de subir a la embarcación, el bastón y la alforja que traía consigo (20.2), mientras que en el segundo diálogo de la obra, Menipo es caracterizado, precisamente, porque en la alforja llevaba lo que Diógenes le había pedido, los altramuces y algo de la cena de Hécate (2.3). Finalmente, pese a que a lo largo de los Diálogos de los muertos se repite constantemente que una vez se ha entrado al Hades no se puede regresar al mundo superior (8.2), Menipo, que ha cruzado la laguna en DMort. 2, debe cruzarla de nuevo, lo cual no resulta coherente con el recorrido descrito en la obra.

DMort. 24 presenta un problema semejante. A pesar de poner en escena al pirata Sóstrato que se defiende ante Minos de sus crímenes argumentando el determinismo de las decisiones de las Moiras, este diálogo está situado en medio del bloque dedicado a los héroes homéricos. No se puede relacionar a Sóstrato con ningún grupo de los personajes que aparecen en el resto de los diálogos. Del mismo modo, al contrario del resto de los Diálogos de los muertos en que Éaco es el juez principal del Hades, en este diálogo es Minos quien toma el papel preponderante ${ }^{43}$. Por otro lado, el motivo del determinismo de la Moira se encuentra también en 27.2, en el que Protesilao explica a Éaco los motivos por los que desembarcó el primero de las naves en Troya. La repetición de este tema en dos diálogos distintos tampoco parece coherente con la estructura del conjunto.

También DMort. 25 presenta dificultades a causa de repeticiones temáticas. Colocado entre el bloque dedicado a los héroes homéricos, en este diálogo Aníbal y Alejandro discuten por saber cuál de los dos merece la primacía entre los generales. Para tal propósito, uno y otro detallan sus principales gestas militares. Se repite, pues, la escena de DMort. 12, en la que Alejandro relataba sus mejores batallas a su padre Filipo. Incluso en la ordenación de la familia $\beta$ en la que el diálogo se emplaza al lado de los otros dos centrados en la figura del rey macedonio, la repetición de contenido nos hace pensar que no parece probable que este diálogo formara parte de la concepción unitaria original de la obra.

${ }_{43}$ En $V H$ 2.27, en cambio, es Radamantis el juez que adquiere el protagonismo y actúa como interlocutor con Luciano. 
Al lado de estas razones basadas en la coherencia estructural del conjunto de la obra, otras razones de crítica textual, léxicas, estilísticas y de contenido que pensamos detallar en un próximo trabajo avalarían la posibilidad de considerar estos tres diálogos como interpolaciones posteriores. Según esta hipótesis DMort. 20 y 24 tienen el aspecto de ser paráfrasis ${ }^{44}$ de las obras menipeas de Luciano, como La travesía, Caronte, Menipo, y, en especial el diálogo entre Sóstrato y Minos, de Júpiter Rebatido. El tercer diálogo puesto en duda, DMort. 25, parece ser un ejercicio escolar de nivel avanzado, una synkrisis ${ }^{45}$, basada en lengua y estilo en los Diálogos de los muertos de Luciano $^{46}$ y en la famosa escena de la literatura grecolatina en que Aníbal y Escipión conversan sobre los mejores generales de la historia ${ }^{47}$. Posiblemente, estas interpolaciones podrían haber sido incorporadas a la colección en el momento en que los copistas recopilaron las obras de Luciano. No resulta inverosímil pensar que las miniaturas que forman los Diálogos de los muertos, al tener suficiente entidad humorística y de sentido cada una de ellas, pudieran haber sido leídas en ocasiones de manera individual o seleccionadas para crear antologías, de manera que el conjunto unitario se fuera debilitando y las piezas pasaran a circular independientemente. Esto podría explicar, también, el distinto orden que presentan las dos familias. Es posible que, mientras que la familia $\gamma$ mantuvo el orden original a pesar de haber incorporado las tres interpolaciones, la familia $\beta$ agrupara de manera distinta los diálogos que habrían sido hallados por separado.

Fuera como fuera, los Diálogos de los muertos contienen suficientes evidencias internas para que consideremos que fueron concebidos y presentados en público por Luciano - no sabemos si en audiciones o en forma de librocomo una obra unitaria y cerrada, donde las distintas piezas que la forman

${ }^{44}$ Cf. Theo, Prog. 15, y Patillon y Bolognesi 1997, pp. 107-110.

45 Tal como explican los manuales de Theo, Prog. 112-115, Hermog., Prog. 18-20 y Aphth., Prog. 10. 31-33, la synkrisis es el ejercicio escolar basado en la comparación de dos personas u objetos con el fin de determinar cuál es mejor; cf. Webb 2001, p. 294.

${ }^{46}$ A pesar de la fama de anticristiano que Luciano tenía entre los bizantinos, Johannes Georgides y Tomás Magister ya lo utilizaron como fuente para sus materiales docentes, lo que propició que algunas de las obras del Sirio, especialmente los Diálogos de los muertos, se utilizaran en las escuelas de Bizancio; cf. Robinson 1979, pp. 68-80, Wilson 1983, p. 186, y Zappala 1990, p. 25.

${ }^{47}$ Cf. Baldwin 1990. 
están interrelacionadas las unas con las otras, de manera que cada diálogo se une al anterior y al siguiente por un hilo narrativo común y por referencias metatextuales que enlazan las conversaciones. Luciano dibuja, de este modo, un viaje por el Hades en una historia completa de principio a fin, donde cada diálogo tiene su lugar. Así pues, Luciano reelabora una vez más los géneros literarios de su época, ayudando a desarrollar un tipo de novela que, en su aspecto, resulta más parecida a una obra dramática que a una narración.

\section{BIBLIOGRAFÍA}

Allinson, F. G. 1926: Lucian Satirist and Artist, Massachusetts, Marshall Jones.

Alsina, J. 1966: Luciano. Obras, vol. II, Madrid, CSIC.

Anderson, G. 1976a: Lucian. Theme and Variation in the Second Sophistic, Leiden, Brill.

Anderson, G. 1976b: Studies in Lucian's Comic Fiction, Leiden, Brill.

Anderson, G. 1996: «Lucian Verae Historiae», en Schmeling, G. (ed.), The Novel in the Ancient World, Leiden, Brill, pp. 555-561.

André, J. M. y Baslez, J. F. 1993: Voyager dans l'Antiquité, París, Fayard.

Baldwin, B. 1961: «Lucian as Social Satirist», CQ 11.2, pp. 199-208.

Baldwin, B. 1973: Studies on Lucian, Toronto, Hakkert.

Baldwin, B. 1990: «Alexander, Hannibal, and Scipio in Lucian», Emerita 58.1, pp. 51-60.

Beaupère, T. 1967: Philosophes à l'encan, París, Les Belles Lettres.

Bellinger, A. R. 1928: «Lucian's dramatic technique», YClS 1, pp. 3-40.

Bianchetti, S. 1998: Pitea de Massalia, L'Oceano, Pisa, Istituti Editoriali e Poligrafici Internazionali.

Bompaire, J. 1958: Lucien écrivain, imitation et création, París, Boccard.

Bompaire, J. 1993: Lucien. Oeuvres I, París, Les Belles Lettres.

Bompaire, J. 1998: Lucien. Oeuvres II, París, Les Belles Lettres.

Bompaire, J. y Ozanam, A. M. 2009: Lucien. Voyages extraordinaires, París, Les Belles Lettres.

Bouquiaux-Simon, O. 1968: Les lectures homériques de Lucien, Bruselas, Acad. Royale de Belgique.

Branham, R. B. 1989: Unruly eloquence, Cambridge, Harvard University Press.

Brandão, J. L. 2001: A poética do Hipocentauro. Literatura, sociedade e discurso ficcional em Luciano de Samósata, Belo Horizonte, UFMG.

Cabrero, M. C. 2006: Elogio de la mentira: sobre las Narrativas Verdaderas de Luciano de Samósata, Bahía Blanca, EdiUNS.

Camerotto, A. 1998: Le metamorfosi della parola. Studi sulla parodia in Luciano di Samosata, Pisa-Roma, Instituto Editoriali e Poligrafici Internazionali. 
Cribiore, R. 2001: Gymnastics of the Mind. Greek Education in Hellenistic and Roman Egypt, Princeton, Princeton University Press.

Georgiadou, A. y Larmour, D. H. 1998: Lucian's science fiction novel True Histiories, Leiden, Brill.

Gómez Espelosín, F. J. 2009: «Luciano y el viaje: una estrategia discursiva», en Mestre, F. y Gómez, P. (eds.), Lucian of Samosata: Greek writer and Roman citizen, Barcelona, PPU, pp. 169-182.

Hall, J. A. 1981: Lucian's Satire, New York, Arno Press.

Harmon, A. M. 1913: Lucian, Cambridge, Harvard University Press.

Helm, R. 1906: Lukian und Menipp, Leipzig, Teubner.

Hinds, S. 1998: Allusion and intertext; dynamics of appropriation in Roman poetry, Cambridge, Cambridge University Press.

Jacobitz, K. 1836: Luciani Samosatensis Opera, vol. 1, Leipzig, Teubner.

Jufresa, M., Mestre, F. y Gómez, P. 2000: Luciano. Obras, vol. III, Madrid, CSIC.

Macleod, M. D. 1961: Lucian, vol. VII, Cambridge, Harvard University Press.

Macleod, M. D. 1972: Lucian Opera, vol. I, Oxford, Clarendon Press.

Macleod, M. D. 1987: Lucian Opera, vol. IV, Oxford, Clarendon Press.

Miller, P. A. 1994: Lyric Texts and Lyric Consciousness. The birth of a genre from archaic Greece to Augustan Rome, Londres, Routledge.

Morgan, T. 1998: Literate Education in the Hellenistic and Roman World, Cambridge, Cambridge University Press.

Navarro González, J. L. 1992: Luciano. Obras, vol. IV, Madrid, Gredos.

Nilén, N. 1906: Lucianus, Leipzig, Teubner.

Nissen, H. 1888: «Die Abfassungszeit von Arrians Anabasis», Rh. Mus. 43, pp. 236257.

Patillon, M. y Bolognesi, G. 1997: Aelius Théon. Progymnasmata, París, Les Belles Lettres.

Pretzler, M. 2007: «Greek Intellectuals on the Move: Travel and Paideia in the Roman Empire», en Adams, C. y Roy, J. (eds.), Travel, Geography and Culture in Ancient Greece and Near East, Oakville CT, Oxbow.

Reardon, B. P. 1971: Courants littéraires grecs des II et III siècles a. J.-C., París, Les Belles Lettres.

Robinson, C. 1979: Lucian and his influence in Europe, Chapel Hill, University of North Carolina Press.

Roussel, M. 2003: «Voyages extraterrestres chez Lucien», en Duchêne, H. (ed.), Voyageurs et Antiquité classique, Dijon, EUD, pp. 101-109.

Saïd, S. 1994: «Lucien ethnographe», en Billault, A. (ed.), Lucien de Samosate. Actes du colloque international de Lyon organisé au Centre d'études romaines et gallo-romaines, París, Boccard, pp. 149-170.

Schwartz, J. 1965: Biographie de Lucien de Samosate, Bruselas, Latomus. 
Ureña Bracero, J. 1995: El diálogo de Luciano: ejecución, naturaleza y procedimientos de humor, Ámsterdam, Hakkert.

Vilardo, M. 1991: Luciano. Storia Vera, Dialoghi dei morti, Milán, Mondadori.

Webb, R. 2001: «The Progymnasmata as Practice», en Too, Y. L. (ed.), Education in Greek and Roman Antiquity, Leiden, Brill, pp. 289-316.

Whitmarsh, T. 2004: «Lucian», en De Jong, I., Nünlist, R. y Bowie, A. (eds.), Narrators, Narratees, and Narratives in Ancient Greek Literature, Leiden, Brill, pp. 465-476.

Wilson, N. G. 1983: Scholars of Byzantium, Londres, Duckworth.

Zappala, M. O. 1990: Lucian of Samosata in the two Hesperias, Potomac, Scripta Humanistica.

Fecha de recepción de la primera versión del artículo: 19/02/2010

Fecha de aceptación: 14/06/2010

Fecha de recepción de la versión definitiva: 07/11/2010 